\title{
The Spatial Structure and Local Experience of Residential Segregation
}

\author{
Elizabeth Roberto ${ }^{1}$ (D) Elizabeth Korver-Glenn ${ }^{2}$
}

Accepted: 30 March 2021 / Published online: 29 June 2021

(C) The Author(s) 2021

\begin{abstract}
This study examines the extent to which road connectivity and physical barrierssuch as highways, railroad tracks, and waterways-structure spatial patterns of racial and ethnic residential segregation and shape how segregation is locally experienced by residents. Our focus is on physical barriers that are also social boundaries-features of the built environment that reduce physical connectivity and mark a social boundary between geographic areas. We measure residential segregation with attention to the proximity and road connectivity between locations, which allows us to identify areas where physical barriers mark a social boundary between geographic areas with different racial and ethnic compositions. Our approach integrates ethnographic observation of three such areas in Houston, Texas, to investigate residents' perceptions and local experience of social and spatial division. The results reveal that physical barriers are associated with heightened levels of ethnoracial segregation, and residents experience the barriers as symbolic markers of perceived distinctions between groups and physical impediments to social connection. Although barriers like highways, railroad tracks, and bayous are not inherently harbingers of ethnoracial segregation, our study demonstrates that physical barriers can provide the infrastructure for social boundaries and facilitate durable neighborhood racial divisions.
\end{abstract}

Keywords Segregation · Spatial inequality · Built environment · Physical barriers · Social boundaries

Elizabeth Roberto eroberto@rice.edu

1 Department of Sociology, Rice University, 6100 Main Street, MS-28, Houston, TX 77005, USA

2 University of New Mexico, Albuquerque, NM, USA 


\section{Introduction}

The core concern of this research is the extent to which the built environmentincluding road connectivity and physical barriers-structures spatial patterns of racial and ethnic residential segregation and shapes how segregation is locally experienced by residents. Our focus is on physical barriers that are also social boundaries-features of the built environment that reduce physical connectivity and mark a social boundary between geographic areas.

Social boundaries are located along the edges of areas with different racial and ethnic compositions. They frequently overlap with geographic features, such as major streets, and political borders, such as school districts. For example, Anderson (1990) describes "the edge," a boundary along Bellwether Street that separates two communities in Eastern City. "The edge" marks the social and spatial division between middle- and upper-income White residents in the Village and working-class and poor Black residents in Northton. Social boundaries define distinct, segregated areas, but they are nonetheless permeable. They can create opportunities for contact and may also provoke intergroup conflict (Legewie, 2018; Legewie \& Schaeffer, 2016).

By contrast, physical barriers - such as highways, railroad tracks, and waterways - typically prevent or inhibit feelings of social connection and may purport to offer "protection" to residents on one side of the barrier from residents on the other side (Atkinson \& Flint, 2004; Blakely \& Snyder, 1997; Low, 2001; Schindler, 2015). For example, in 1951, the towns of Hamden and New Haven, CT, built a fence along their border to separate a neighborhood of middle-class homeowners in Hamden from three new public housing developments in New Haven. In the years after its construction, the fence was fortified in response Hamden residents' concerns about crimes being committed by New Haven residents and pleas by for a "safety barrier" (Armborst et al., 2017; Bass, 2017; Mueller, 2014). Until its removal in 2014, the 12-foot high, 1,500-foot-long fence cut off all connectivity via sidewalks and roads between the mostly White Hamden homeowners and the predominantly Black public housing residents in New Haven (Mueller, 2014). ${ }^{1}$

Our interest lies at the intersection of social boundaries and physical barriers. While sociohistorical research has shown how physical barriers such as highways were intentionally constructed to separate people socially — by race and/or class (e.g. Connolly, 2014; Feagin, 1988)—-little research has examined how physical barriers and social boundaries converge in contemporary urban contexts. In this study, we build on the strength of examining both the spatial pattern and on-theground experiences of segregation and extend prior work on racial segregation in contemporary urban America. Although the social boundaries between segregated areas carry symbolic meaning and shape inter-group contact, they are still fluid and negotiable and offer the possibility for social connection between groups (Anderson,

\footnotetext{
${ }^{1}$ This area of New Haven is bordered on three sides by a state park, a highway, and the Hamden town dump. The fence along Woodin Street was removed in 2014, despite vocal opposition from Hamden residents. For example, at a Hamden town meeting, a resident living on Woodin Street remarked: "You put a street through, you're jeopardizing the life of everyone in this room" (Appel, 2012).
} 
1990; Hunter, 1974; Hwang, 2016; Legewie, 2018; Suttles, 1972). In contrast, when social boundaries take shape as physical barriers, like freeways with few over- or under-passes and train tracks with few crossings, they are less easily crossed and can become infused with symbolic meaning. When physical barriers provide the infrastructure for social boundaries, patterns of urban segregation can become especially entrenched. Physical barriers combine the strength of symbolic boundaries with the durability of physical infrastructure to render persistent neighborhood racial divisions.

To extend prior research on racial segregation, we measure residential segregation with attention to the proximity and road connectivity between locations, which allows us to identify areas where physical barriers divide urban spaces and are associated with higher levels of segregation (Roberto, 2018). The segregation measure points us to locations where the built environment facilitates both spatial disconnection and social division, but it cannot directly assess how residents perceive the barrier or their feelings of social connection with residents on the other side of the barrier. Therefore, our study also integrates a qualitative component that examines the perceptions and local experience of residents at sites of social and spatial division-the locations identified with the quantitative analysis.

\section{The Mechanisms of Residential Segregation}

Racial residential segregation is a durable feature of American cities (Krysan and Crowder 2017). Scholars have posited several theories to explain its persistence, including racial residential preferences. Members of different racial groups prefer to live with some groups and avoid others, and they make residential choices based on these preferences (Charles, 2006; Howell \& Emerson, 2018; Lewis et al., 2011). Racial discrimination is another key mechanism that shapes how people find homes and where they live. For example, real estate agents tell Asian, Black, Latinx, ${ }^{2}$ and Native American residents about fewer housing options than their White counterparts. Real estate agents also tend to show home buyers and renters of color housing options in neighborhoods of color or multiracial neighborhoods, while they more often show White home buyers and renters homes in White neighborhoods (Ross \& Turner, 2005; Turner et al., 2013). Real estate professionals in other industries, including the appraisal industry, also discriminate against individuals and neighborhoods of color, contributing to racial segregation (Howell \& Korver-Glenn, 2018; Korver-Glenn, 2018a). Another key mechanism of durable racial segregation is economic inequality: groups of color typically make less money and have less wealth on average than their White counterparts, which means they are unable to purchase homes of equivalent value and often end up purchasing in neighborhoods with lower average home values (Flippen, 2004; Thomas et al., 2018). Of course, each of these

\footnotetext{
2 To avoid the problematic colonial overtones of "Hispanic" and gendered implications of "Latino/a," we use "Latinx" throughout the paper unless we are referring to Census ethnoracial classifications or reproducing verbatim respondents' own narratives.
} 
three mechanisms works simultaneously and, in many ways, they reinforce each other (Krysan et al., 2014).

Recently, scholars have theorized that the multiple-stage nature of the housing search process is yet another mechanism contributing to ongoing segregation, whether through consumers' knowledge and successive choices (Krysan and Crowder, 2017) or through market professionals' racialized influence over consumers, the housing search process, and home valuation (Korver-Glenn, 2018a, 2021). With respect to consumers, Krysan and Crowder (2017) have shown how individuals accumulate community knowledge through their lived experiences and social networks, both of which are racialized (i.e. Americans tend to live racially separate lives and have racially segregated networks (Krysan, 2008; Wang et al., 2018)). Even if it remains largely subconscious, this knowledge affects the housing choices people make-indeed, it affects the range of choices they believe they have in the first place. With respect to the housing market, there are many professionals that shape where homes get built, how consumers perceive homes and neighborhoods, which homes they view, whether and under what conditions they access mortgage loans, and how homes and neighborhoods are valued (Besbris, 2020; Korver-Glenn, 2021). Housing market professionals shape the housing search process in racialized ways across consumers' decision-making stages, cumulatively contributing to durable segregation (Korver-Glenn, 2018a).

Yet existing explanations for ongoing contemporary residential segregation have missed a key mechanism that sociohistorical work suggests may matter a great deal: physical barriers. Physical barriers are strong and persistent forms of boundaries. Once in place, they require institutional action to dismantle, including urban planning and infrastructure investment (Jackson, 1985; Mohl, 2002; Schindler, 2015). Many physical barriers were originally constructed with an intention to racially segregate nearby populations (Mohl, 2002; Schindler, 2015; Sugrue, 2005), such as in the selection of routes for interstate highways built during the 1950s and 1960s in many American cities such as Atlanta, Chicago, Houston, and Miami (Feagin, 1988; Mohl, 2002). Moreover, the planning and construction of these highways disproportionately disrupted and demolished Black and Latinx neighborhoods in these cities (Schindler, 2015; Shelton, 2017), shattering local businesses, housing stock, and social networks (Feagin, 1988). Many of these barriers established patterns of racial residential segregation that persist today. For instance, Syracuse city leaders adopted proposed plans for Interstate 81 that would ultimately demolish the predominantly Black $15^{\text {th }}$ Ward community (DiMento \& Ellis, 2012; Semuels, 2015). Moreover, the planning and construction of I-81 helped put into motion decades of increasing racial segregation and poverty concentration in Syracuse (Jargowsky, 2015; Semuels, 2015). Syracuse is now one of the most highly segregated mid-size cities in America-one of what Krysan and Crowder (2017) identify as the "legacy metros," or metropolitan areas with durable, high levels of Black-White segregation and slow integration between 1980 and 2010 .

The built environment of cities continues to evolve, particularly in cities with rapid population and infrastructure growth, such as Atlanta, Phoenix, and Houston. While the ongoing process of building and developing highways, light or freight rail tracks, airports, waterways, and other physical features may be less explicitly racist 
than in previous decades, such features may nevertheless still separate city-dwellers socially. For example, a small body of work suggests that physical barriers influence residential decision-making by providing clear divisions between spaces and facilitating symbolic, "conceptual distinctions" (Lamont \& Molnar, 2002:168) among places. These physical-symbolic distinctions then yield agreement among residents, real estate agents, and other institutional actors about where one neighborhood ends and another begins (Ananat, 2011; Bader \& Krysan, 2015; Krysan \& Bader, 2009). In theory, such agreement then influences actors' behaviors (e.g. where to purchase homes, where to construct homes, where to locate or access amenities, and so on). As a result, the presence of these barriers can result in distinct social conditions and experiences_-such as economic and educational opportunities (Besbris et al., 2015; Owens, 2016) - for individuals on opposite sides, as exemplified by the common metaphor, "the other side of the tracks."

Physical barriers-and those who support their construction-also purport to offer "protection" to residents on one side of the barrier from residents on the other side (Atkinson \& Flint, 2004; Blakely \& Snyder, 1997; Low, 2001; Schindler, 2015). This work suggests that residents may use physical barriers to signal race and play on racist fears without saying explicit racist epithets. Physical barriers contribute to the clarity or "legibility" of the cityscape (Lynch, 1960), in particular, the ease with which residents recognize coherent patterns of racial segregation.

In short, physical barriers are a key yet understudied mechanism of durable social boundaries in twenty-first century urban America. The present paper focuses specifically on the relationship between physical barriers and ethnoracial boundaries. Further, we argue that unless we pay attention to the power of the built environment to shape social and spatial division, the expanding infrastructure of such cities may further exacerbate racial residential segregation. This paper thus examines whether and to what extent physical barriers are associated with racial residential segregation in Houston, Texas. Specifically, we investigate the extent to which disconnectivity in the road network and physical barriers between locations divide urban spaces and spatially structure patterns of racial and ethnic residential segregation in Houston, Texas. We also examine how this division shapes the local experience of segregation for residents. To our knowledge, no previous studies have combined such an examination with a consideration of how segregation and physical barriers are experienced by residents.

Although previous research suggests a causal relationship between the construction of barriers and increases in segregation levels (Mohl, 2002; Schindler, 2015; Sugrue, 2005), the purpose of our study is descriptive. To that end, we examine both the extent to which disconnectivity and physical barriers are associated with higher levels of ethnoracial segregation and the processes through which physical barriers influence the lived experiences of Houston's residents. The quantitative component of our analysis uses 2010 decennial census data and applies a novel measure of segregation and spatial connectivity (Roberto, 2018), and the qualitative component includes a multi-site ethnography and in-depth interviews in urban Houston.

We describe our results in three parts. First, we present an overview of the quantitative findings on racial and ethnic segregation, the geographic scale of segregation patterns, and the relationship between disconnectivity and physical barriers and 
segregation levels. Second, we describe our qualitative findings, focusing on how Houston residents understood the built environment and its relation to social and symbolic boundaries and illuminating its salience for their everyday lives. Third, we blend an in-depth quantitative analysis of three neighborhoods with a qualitative analysis of how local residents and other stakeholders experienced and navigated social and spatial division. Overall, our results reveal that physical barriers are associated with heightened levels of ethnoracial segregation in Houston. Moreover, Houstonians experience such barriers as physical impediments as well as signposts of ethnoracial division. Physical barriers impeded connectivity between racially distinct groups and, furthermore, were understood as symbolic markers of perceived distinctions between groups.

\section{Data and Methods}

\subsection{Research Setting}

We chose to study Houston for two main reasons. First, typifying urbanization in the U.S. South and Southwest-and unlike cities in the Northeast (e.g. New York) and Midwest (e.g. Chicago)_Houston has decentralized and privatized operations and urban planning, resulting in urban sprawl and the construction and fortification of a massive system of highways and major roads. Relatively little planning and investment in mass transit has occurred (Emerson and Smiley, 2018; Feagin, 1988). Historically, the process of transport network development in Houston disproportionately has affected communities of color (Feagin, 1988). Additionally, Houston, also known as the 'Bayou City,' is laced with hundreds of miles of bayous, many of which have been channelized with concrete. The bayous, along with Houston's massive port, thus add an intriguing dimension to understanding the relationship between the built environment and segregation patterns.

Second, analyzing the spatial structure of segregation in Houston allows us to examine how distinct ethnoracial groups experience physical barriers. The city's population is ethnically and racially diverse, with 23 percent Black, 44 percent Latinx, and 26 percent White residents. Houston has had a continuous in-flow of immigrants from Latin America, Asia, and Africa over the past 30 years. As of 2015, 28.5\% of its population was foreign-born (U.S. Census Bureau, 2015). Non-White and non-Western immigrants to Houston are also entering a broader national context that is increasingly hostile to them (Doherty, 2016). Within this broader context of cultural backlash in the U.S., it is important to explore whether physical division is associated with residents' perceptions and experiences of social division.

Within Houston, we chose to foreground three specific neighborhoods-Fifth Ward, Heights, and Northside-for several theoretically important reasons. We highlight two of these reasons here. First, each neighborhood has a different mix of racial and ethnic groups, allowing us to compare how physical barriers may work differently for neighborhoods with distinct racial compositions. Table 1 
Table 1 Demographic characteristics for three Houston neighborhoods and the city

\begin{tabular}{lllll}
\hline & Fifth ward & Heights & Northside & City of Houston \\
\hline Total population (n) $^{\mathrm{a}}$ & 19,823 & 40,865 & 26,831 & $2,099,451$ \\
Hispanic/Latino (\%) $^{\mathrm{a}}$ & 43.5 & 39.0 & 83.2 & 43.8 \\
Non-Hispanic Black (\%) $^{\mathrm{a}}$ & 52.4 & 3.5 & 8.2 & 23.1 \\
Non-Hispanic White (\%) $^{\mathrm{a}}$ & 2.6 & 53.6 & 7.7 & 25.6 \\
Housing units owner-occupied (\%) $^{\mathrm{b}}$ & 37.2 & 58.3 & 43.0 & 44.5 \\
Over-25 adults with GED/high school diploma or & 62.5 & 86.3 & 56.5 & 75.9 \\
$\quad$ above $(\%)^{\mathrm{b}}$ & & & & \\
Over-25 adults with bachelor's degree or higher $(\%)^{\mathrm{b}}$ & 9.7 & 54.8 & 8.7 & 29.8 \\
\hline
\end{tabular}

Source: Authors' calculations

${ }^{a}$ Population data are from the 2010 decennial census

${ }^{\mathrm{b}}$ Population estimates are from the ACS 2014 5-year estimates
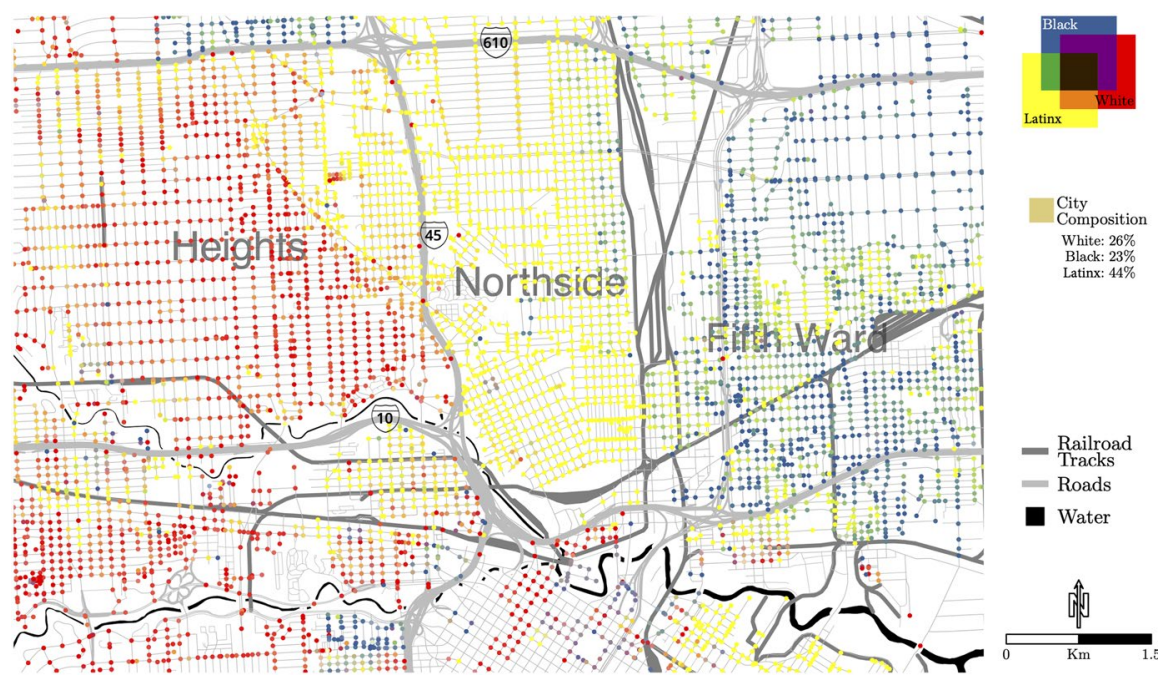

Fig. 1 Black, Latinx, and White population in the heights, northside, and fifth ward neighborhoods of Houston, TX in 2010

shows the demographic characteristics of these neighborhoods ${ }^{3}$ and Fig. 1 is a map of the Black-Latinx-White racial composition for locations in the neighborhoods. The blue, yellow, and red colors are blended to match the composition Black, Latinx, and White residents in each location. The box labeled "City Composition" indicates the color that matches the Black-Latinx-White composition of the city-if there were no segregation in Houston, each location would match the color of the "City Composition" box. Second, each of these areas is bordered by major freeways on at least two sides and contains or is bordered by at least

\footnotetext{
3 We define the boundaries of each neighborhood based on input from residents.
} 
one bayou, which allows us to examine if these physical features contribute to higher levels of segregation and, if so, how these barriers matter locally to residents. Together, these characteristics make these three neighborhoods ideal for our exploratory analysis of how physical barriers shape residents' experience of segregation.

\subsection{Quantitative Data and Method}

There has been increasing attention on the development of methods that capture the spatial dimensions of residential segregation, such as the spatial arrangement of segregated neighborhoods and the geographic scale or relative size of segregated areas (Brown \& Chung, 2006; Folch \& Rey, 2016; Fowler, 2015; Logan, 2017; Morrill, 1991; O’Sullivan \& Wong, 2007; Reardon \& O’Sullivan, 2004; White, 1983; $\mathrm{Xu}$ et al., 2014). Most newly developed approaches measure the proximity between locations in terms of contiguity or straight line distance, but do not consider if or how well the locations are connected via the road network. In other words, they do not consider how the built environment affects the proximity and connectivity of locations. To address this shortcoming, we use the Spatial Proximity and Connectivity (SPC) method developed by Roberto (2018).

The SPC method incorporates spatial features of the built environment, including the road connectivity and physical barriers between locations, into the measurement of segregation and compares segregation measures that consider or do not consider such features. This is an important feature of the SPC method because physical barriers, such as fences, highways, and dead-end streets, have been used as mechanisms to reinforce or exacerbate segregation by facilitating greater separation between ethnoracial groups in nearby areas (e.g., Jackson, 1985; Mohl, 2002; Schindler, 2015; Sugrue, 2005).

Following the SPC method, we first link the geographic data for census blocks and roads using publicly available population data from the 2010 decennial census (U.S. Census Bureau, 2011) and the TIGER/Line shapefiles for blocks and roads (U.S. Census Bureau, 2012). ${ }^{4}$ With this data, we estimate the population count and composition for each node (i.e., the intersections of roads) in the road network. We then calculate the shortest path along the road network between all pairs of nodes, as well as the straight line distance between all pairs of nodes.

\footnotetext{
${ }^{4}$ Census blocks are typically bounded by street or road segments on each side and often correspond to the size of a city block in urban areas. They are the smallest unit of census geography for which population data are publicly available.
} 
We construct local environments, or "egocentric neighborhoods" (Lee et al., 2008), around each node. ${ }^{5}$ We vary the reach (i.e., the distance in each direction from a given node) of the local environments from 0.25 to $6 \mathrm{~km}$ to measure segregation at multiple geographic scales. We define the reach of the local environments using each distance measure - road network distance and straight line distance — to create a set of local environments for all nodes at each reach and with each distance measure. We selected reaches of $0.25 \mathrm{~km}, 0.5 \mathrm{~km}, 1 \mathrm{~km}, 2 \mathrm{~km}, 3 \mathrm{~km}, 4 \mathrm{~km}$, and $6 \mathrm{~km}$ for this study. Local environments with a reach of 1 to $2 \mathrm{~km}$ approximate the size of the neighborhoods we selected for our local analysis and ethnographic research.

Next, we calculate the population composition in the local environment of each node, separately for each reach and each distance measure. This provides the information necessary to measure the level of segregation of each local environment and for the city as a whole, with a separate set of results for each reach and each distance measure. To measure the level of segregation, we use the Divergence Index (Roberto, 2016), which measures the difference between the population composition of each local environment and the city's overall composition. The values of the Divergence Index represent how surprising the composition of a local environment is, given the overall population composition of the city. The Divergence Index equals zero-its minimum value - when there is no difference between the local and overall population composition, whereas greater differences produce higher values and indicate a greater degree of segregation. Local values of the Divergence Index will reach their maximum value when the smallest group in a city is 100 percent of the local population.

The Divergence Index measures the same concept of segregation as the Dissimilarity Index. Both indexes measure the evenness dimension of segregation (Massey \& Denton, 1988) by comparing the residential distribution of groups to an even distribution in which groups are distributed proportionally across residential environments. We use the Divergence Index to measure the level of segregation in the local environment of each node, and we calculate separate results for each reach and each distance measure. We focus on the segregation of Black, Latinx, and White residents in the city of Houston, the city's three largest racial and ethnic groups. ${ }^{6}$ (See Appendix for more details about the Divergence Index and an overview of segregation levels in Houston.)

\footnotetext{
${ }^{5}$ Local environments can span bodies of water, such as a rivers and lakes, and will include the population on the other side of the water if it is within the specified reach (defined by the road network or straight line distance). For locations near the municipal boundary of the city, we limit the local environments to be within the city by only including the locations within the specified reach (defined by road network or straight line distance) that are inside the city. For example, if the reach of local environments is $1 \mathrm{~km}$, the local environment of a node within $1 \mathrm{~km}$ of the municipal boundary will not include the population of nearby municipalities, even if they are within $1 \mathrm{~km}$ of the node. For more on this decision, see Roberto (2018).

${ }^{6}$ Using U.S. Census Bureau's categories of race and ethnicity, we define three ethnoracial groups: Hispanic/Latino of any race ("Latinx"), non-Hispanic Black ("Black"), and non-Hispanic White ("White"). The population of Houston is, 23 percent Black, 44 percent Latinx, and 26 percent White.
} 


\subsection{Qualitative Data and Method}

We use qualitative methods to observe how physical barriers affect the daily lives of Houston residents and to provide a substantive interpretation of the quantitative differences in segregation measures. Importantly, initial qualitative data collection efforts were not designed with physical barriers and segregation in mind; rather, we were interested in questions related to urban redevelopment and housing markets. Yet references to physical barriers and experiences of isolation and separation repeatedly emerged during data collection. For instance, 72 unique interviewed respondents (51 percent of the 141 total respondents) $)^{7}$ referenced five types of physical barriers without interviewer prompting 127 times. $^{8}$ Thus, without sampling on the dependent variable, we have rich data on how the spatial structure of segregation matters, and for whom it matters.

Ethnographic research was conducted in multiple urban Houston areas, including two years of fieldwork in Houston's Northside neighborhood and one year of ethnographic research that included Houston's Fifth Ward and Heights neighborhoods. The ethnographic component included participant observation at local neighborhood events, such as festivals and neighborhood association meetings, as well as observations of daily patterns of activity at local parks, for example. This component also included collecting photographs, brochures, and other media related to each neighborhood.

Additionally, in-depth interviews were conducted with 141 people who either lived or (occasionally) worked in at least one of the three neighborhoods, among many other urban Houston areas. In-depth interviews were conducted using a purposive, case-study sampling approach, in which each participant was viewed as a single 'case' (Small, 2009). Table 2 provides summary demographic information for the 141 respondents. Each interview, or case, yielded data that was used to refine interview questions and subsequent respondents were intentionally chosen to yield a sample that reflected differences along multiple axes (e.g. gender, race, immigrant generation) (Small, 2009). Convergence across the interview and ethnographic data strengthens our confidence in the reliability of the findings (Lareau, 2012; Small, 2009).

Ethnographic fieldwork and in-depth interviews in Northside were conducted between January 2013-December 2013 and February 2015-February 2016. Ethnographic fieldwork and in-depth interviews in Fifth Ward and Heights were conducted

\footnotetext{
${ }^{7}$ Of these 72,51 percent $(n=37)$ were women, 11 percent $(n=8)$ were Black, 44 percent were Latinx $(n=32)$, and 39 percent $(n=28)$ were White, roughly mirroring the demographic characteristics of the overall interview sample (see Table 2).

${ }^{8}$ The five types of barriers ( $n=$ number of unique mentions) were: highways $(n=47)$, railroads/railroad tracks $(n=27)$, bayous $(n=20)$, gates/fences $(n=17)$, and bridges $(n=15)$. Note that some respondents brought up the same or same type of barrier multiple times during their interview; we do not count these repeat mentions. There were no particular questions around which unprompted mention of physical barriers clustered. Instead, references to physical barriers occurred in response to questions as diverse as, "How would you describe the neighborhood?" "What is the relationship between neighborhood associations and the housing market?" and "Why do you think the neighborhood racial composition has changed dramatically over the past 15 years?" among many others.
} 
Table 2 Demographic characteristics for in-depth interview respondents
Interview

respondents

(n)

\begin{tabular}{lr} 
Gender & \\
Women & 71 \\
Men & 70 \\
Race & \\
Asian & 5 \\
Black & 16 \\
Latinx & 63 \\
Multiracial & 2 \\
Non-Hispanic White & 55 \\
Immigrant generation ${ }^{\mathrm{a}}$ & \\
1 & 3 \\
1.5 & 9 \\
2 & 13 \\
3 or later & 31 \\
Average age & 47 \\
Total & 141 \\
\hline
\end{tabular}

Source: Authors' calculations

a Immigrant generation describes the Latinx respondents; so few other-race respondents related an immigration history that reporting such information could betray respondent confidentiality. Six Latinx respondents did not report their immigrant generation; one Latinx respondent reported that her ancestors had lived in Texas prior to 1845 , when the state was still part of Mexico's territory, and thus did not feel she had an immigrant generation to report

between February 2015-February 2016 (see Korver-Glenn, 2014, 2015, 2018a). All qualitative data collection received IRB approval and all research participants were offered a small gift card incentive for their participation in the study.

The ethnographic and interview data were collected as part of two distinct studies with different research questions, neither of which focused on physical barriers or their import for respondents' lived experiences (see Korver-Glenn, 2014, 2015, 2018b). However, given the unprompted and surprising prevalence of physical barriers across these two datasets, we reanalyzed all qualitative data concurrent with the present paper's quantitative analysis in order to focus on how residents and nonresidents ${ }^{9}$ perceived and experienced physical barriers and segregation. As we did so-and in alignment with an abductive analysis approach — we engaged a different body of literature on physical barriers, the built environment, and social boundaries

\footnotetext{
9 We include non-resident stakeholders, including real estate agents and local business owners among others, because they are positioned not only to share their own experiences of working and navigating physical barriers in each area but also have the potential to shape local (prospective) residents' perceptions and experiences as well (see Besbris 2016; Besbris and Faber 2017; Korver-Glenn 2018b).
} 
that we had not anticipated when the data were originally collected (Timmermans \& Tavory, 2012; see also Lara-Millán and Gonzalez Van Cleve (2017) for another example of reanalyzing data with an eye to new themes and literatures). We used ATLAS.ti software to merge all interview and ethnographic data into a single analytic unit. Then, we recoded all data specifically with an eye to physical barriers and how they mattered for neighborhood stakeholders. The most common physical barriers mentioned by interview respondents were highways, railroads/railroad tracks, bayous, gates/fences, and bridges (see also footnote 8). Physical barrier codes co-occurred with ethnoracial separation/distinction and access or lack of access to amenities codes, among others.

In what follows, we begin with our quantitative analysis, examining patterns of disconnectivity in these areas and Houston overall. Then, we describe how local stakeholders described physical barriers in and between Fifth Ward, Heights, and Northside, illuminating their significance for these individuals. Finally, we pair our qualitative and quantitative data to provide a more in-depth examination of our findings for each neighborhood, showing how physical barriers matter for individuals' lived experiences. Pairing the qualitative and quantitative analyses enables us to triangulate across multiple data sources to answer meaningful questions about both the spatial patterns and processes of segregation (Pearce, 2012; Small, 2011).

\section{Results}

\subsection{Spatial Patterns of Segregation}

To begin, we describe the level of segregation between Black, Latinx, and White residents at various geographic scales in the Fifth Ward, Heights, and Northside neighborhoods, and examine the association between the connectivity and physical barriers between locations and the level of segregation in each neighborhood. This allows us to compare the levels of segregation and the differences between road distance and straight line distance segregation measures, which indicates whether road connectivity and physical barriers are associated with higher levels of segregation in each neighborhood.

Figure 2 a shows the road distance segregation results for each neighborhood and for the city of Houston overall. Across all reaches of the local environments, the road distance segregation measure is highest in Fifth Ward, followed by Heights, and Northside. The level of road distance segregation in Fifth Ward is higher than the city-level average when the reach of local environments is less than $3 \mathrm{~km}$. The rate of decrease in the level of segregation as the reach of local environments increases is steeper for Fifth Ward than for the city-level average. All three neighborhoods show a similarly steep rate of decrease.

The city-level trend is indicative of a more macro-scale pattern of segregation, characterized by racially homogenous areas that encompass large sections of a city. Patterns of macro-scale segregation tend to show modest decreases in segregation as the reach of local environments increases, indicating that, on average, the population 

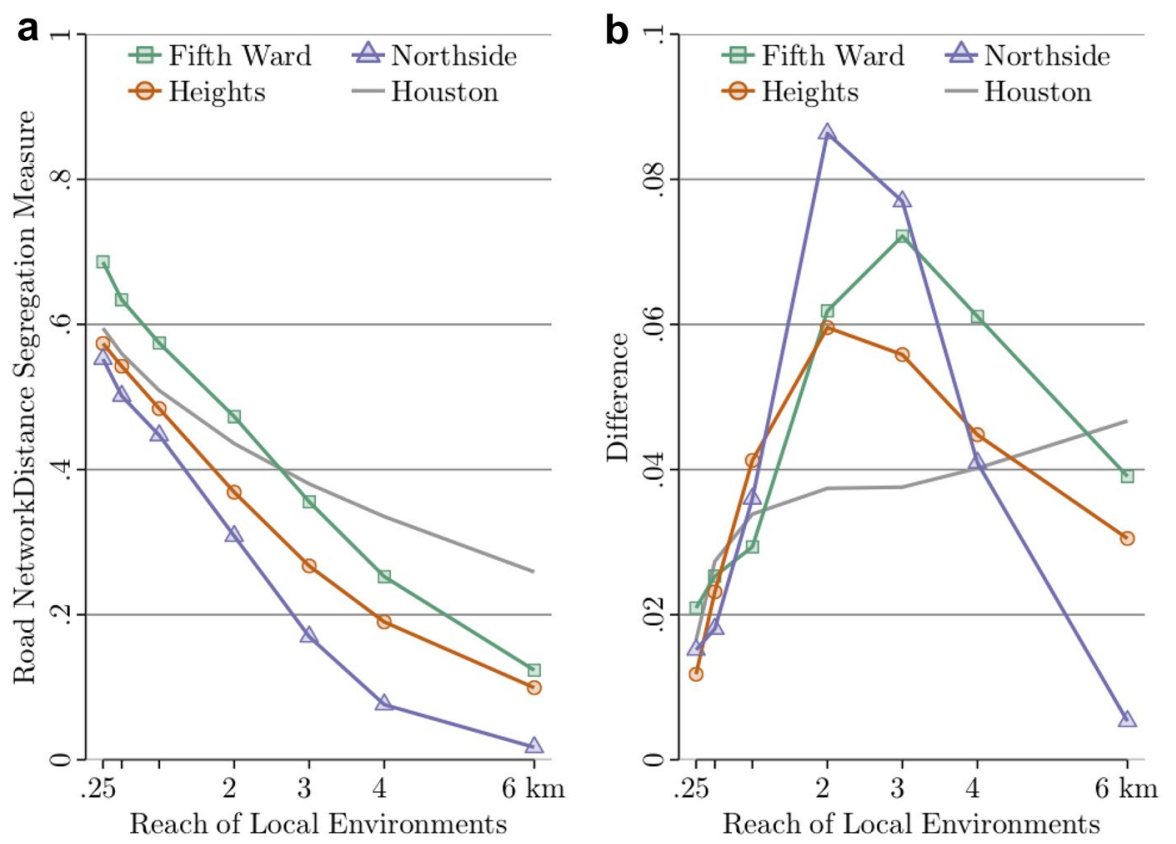

Fig. 2 a Road distance segregation measure by neighborhood (Black-Latinx-White segregation), b Difference between road distance and straight line distance segregation measures by neighborhood (BlackLatinx-White segregation)

composition of larger local environments is only modestly more representative of the city's composition than smaller local environments.

In contrast, the neighborhoods exhibit a trend indicative of a more micro-scale pattern of segregation, characterized by a patchwork of racial and ethnic enclaves. Patterns of micro-scale segregation tend to show steep decreases in segregation as the reach of local environments increases and segregation approaches zero when size of the local environments is larger than typical size of a racial and ethnic enclave in the city.

On average in Houston, there is still a substantial degree of segregation in local environments when their reach is $6 \mathrm{~km}(0.26)$, which indicates that a reach of $6 \mathrm{~km}$ is not sufficient for local environments to include a microcosm of the city's population. In Northside, segregation in local environments with a reach of $6 \mathrm{~km}$ approaches zero (0.02), and the level of segregation in Heights and Fifth Ward is 0.10 and 0.12, respectively. The contrast between the city-level and neighborhood segregation trends suggests that although large, racially homogenous areas tend to dominate the city's spatial pattern of segregation, there are areas that have more granular patterns of segregation than the city at-large. Within such places, it is possible that road disconnectivity and physical barriers facilitate separate spaces and physical division between ethnoracial groups. To investigate this possibility, we examine the differences between the road distance and straight line distance segregation measures. 
The average difference between the road distance and straight line distance segregation measures in Houston ranges from 0.02 to 0.05 for local environments with reaches of $0.25 \mathrm{~km}$ to $6 \mathrm{~km}$. The differences in segregation measures tends to be larger (on average) in the neighborhoods than in the city overall, with the largest maximum difference in Northside (0.09), followed by Fifth Ward (0.07) and Heights (0.06). (See Fig. 2b.) Across all three neighborhoods, the differences are largest for local environments with reaches of 2 and $3 \mathrm{~km}$. The difference between the segregation measures is a population-weighted average of all of the nodes in each neighborhood, including those in areas where no physical barriers are present. In areas with no barriers, there will be no difference between the two segregation measures, therefore, even small positive differences in the average results are meaningful and suggest that road disconnectivity and physical barriers facilitate greater separation between ethnoracial groups and higher levels of segregation. Indeed, when we zoom-in to examine locations within each neighborhood, we find differences that are several times larger than the average difference at the neighborhood- or city-level. In the next section, we describe how local residents and stakeholders perceived local physical barriers, and then we pursue these findings further by mapping the local differences and connecting them to the experiences of residents in each neighborhood.

\subsection{Perceptions of Physical Barriers}

Next, we provide an overview of how physical barriers emerged in the context of interviews and fieldwork, illustrating the salience and substantive significance of physical barriers and segregation for individuals in the Fifth Ward, Heights, and Northside neighborhoods. These data are exemplary of how respondents -72 of whom mentioned physical barriers without prompting 127 times-perceived and experienced physical barriers, such as highways and railroad tracks, as markers of ethnoracial difference and separation.

One such example emerged during an interview with Morris, a White Heights resident and real estate agent. In addition to taking pride in his neighborhood, Morris also sold the area to home buyers. As he described the Heights and nearby areas during his interview, Morris explained:

If you're west of [Interstate] 45, you're north of what? Montrose, West University, you know. [Interstate 45] is kind of that Mason-Dixon line, that dividing line that says no, you don't want to go east of 45 . Because east of 45 is pretty rotten.

Morris references specific areas that, like the Heights, are west of I-45. These two areas, Montrose and West University, are also predominantly White. In the context of the interview, being west of I-45-and close to other White areas also west of I-45-was part of what made the Heights desirable in contrast to what he believed were the 'rotten' areas east of I-45. Additionally, while Morris did not specifically mention the racial demographics of either the Heights or Northside areas, he described I-45 as the 'Mason-Dixon line'-a pre-Civil War signal of the division between slave and free states - to signal this racial distinction. Interstate 45 emerged 
repeatedly as a physical barrier that marked ethnoracial separation between the Heights (west of the barrier) and Northside and Fifth Ward (east of the barrier).

Similarly, major highways also featured prominently in respondents' perceptions and experiences of Fifth Ward. Amanda, a 40-something Latina real estate agent active in the Heights and other Houston neighborhoods, described Fifth Ward by referencing State Highway 59 and Interstate 10. She explained that these highways were:

...kind of the great wall there... where you just kind of say-you know-it's not an area that you encourage people to invest in yet.

For her, these highways were a formidable barrier against investment. The reason, according to Amanda, was that these highways, or the 'great wall,' sectioned off a "completely different demographic," making Fifth Ward a much harder sell than other nearby areas.

In addition to highways, fieldwork and interview data revealed that local stakeholders perceived railroad tracks and bayous - especially in Fifth Ward-as physical barriers that fostered separation between racially distinct areas. For example, in 2010, the Fifth Ward Community Redevelopment Corporation (Fifth Ward CRC) conducted a qualitative Fifth Ward housing study based on interviews with 62 Fifth Ward residents and dozens of non-resident stakeholders as part of the area's participation in the City of Houston Tax Incremental Reinvestment Zone (TIRZ) program (Fifth Ward CRC 2011). This report, which we used and analyzed as field data for the present study, explained that.

Freeways, railroads, Buffalo Bayou, and large-scale industrial properties also separate the Study Area from Downtown and other emerging areas such as East Downtown (EaDo) and the East End. The physical separation and lack of connectivity to revitalized areas can engender a sense of isolation from the vitality of the urban core (Fifth Ward CRC 2011:50).

Downtown, EaDo, and East End are all part of the 'urban core' the report references. Importantly, each of these areas is racially distinct from the Fifth Ward's predominantly Black population: downtown residents are largely White while EaDo and East End residents tend to be Latinx. Moreover, although highways, railroad tracks, and bayous are not inherently harbingers of ethnoracial segregation, the "lack of connectivity" across such urban features does suggest that they foster "isolation" by disconnecting the residents of different areas.

With this introduction to how local residents and stakeholders perceived local physical barriers, we now turn to our mixed-methods analysis of how physical barriers structure the experience of ethnoracial segregation in the Fifth Ward, Heights, and Northside neighborhoods. 


\subsection{How Connectivity and Physical Barriers Affect Lived Experiences of Segregation}

Finally, we zoom in on particular areas of Houston's Fifth Ward, Heights, and Northside neighborhoods where quantitative analyses indicate physical barriers structure patterns of segregation. We draw on these quantitative analyses and pair them with qualitative analyses to show how these barriers matter for local stakeholders. We found that local stakeholders perceived and treated some physical barriers, such as the major freight train tracks cutting through Fifth Ward and Interstate 45 (between Northside and the Heights neighborhoods), as strong physical markers of racial and, at times, class division that kept these areas and their residents socially disconnected from each other. Other physical barriers, such as a wide swath of undeveloped, former industrial rail yard in the southern end of the Northside neighborhood, cut residents off from downtown and other nearby areas and amenities.

First, local stakeholders perceived and treated physical barriers as strong physical markers of racial and, at times, class division that kept these areas socially disconnected. In Fifth Ward, residents perceived major freight train tracks as the physical manifestation of racial division. A longtime resident of Fifth Ward, Joan, had grown up in the neighborhood during the era of school desegregation. Joan a middle-aged Black accountant, described how the railroad tracks promoted division between Fifth Ward's Black population and Latinx Denver Harbor to the east. As she recalled, the only reason she or her Black counterparts walked across the tracks into Denver Harbor (thereby circumventing the much longer road route with rail crossing signals) was to access necessary amenities, such as a grocery store. But, she said,

...you get back across that track because you didn't fool around over there.

And [Hispanics in Denver Harbor] didn't fool around over here. ... You know, so the first time - it's been so long ago now - the first time that a Hispanic family bought a house on this side [of the tracks in Fifth Ward], it was like what in the hell is wrong with them [laughs].

Consistent with Joan's experience, the map in Fig. 3 shows that there are locations in Fifth Ward where there are large differences between the road distance and straight line distance segregation measures. The map shows locations with differences greater than 0.1, with darker colors indicating larger differences. The differences seen in Fig. 3 indicate that road connectivity and physical barriers are associated with higher levels of segregation, and many of the locations with the largest differences are situated near railroad tracks, as well as interstate highways and waterways. This suggests that in these locations, residents are less connected to other residents on "the other side of the tracks" and that this lack of connectivity is associated with higher levels of segregation. In Joan's view, the freight rail tracks were a visible and difficult-to-cross barrier that encouraged division between local Black and Latinx Houstonians.

Like the freight train tracks in Fifth Ward, Interstate 45-dividing Heights and nearby areas on the west from Northside on the east-restricted connectivity between two racially distinct areas. The map in Fig. 4a shows the ethnoracial composition in sections of the Heights and adjacent Northside neighborhoods, with 


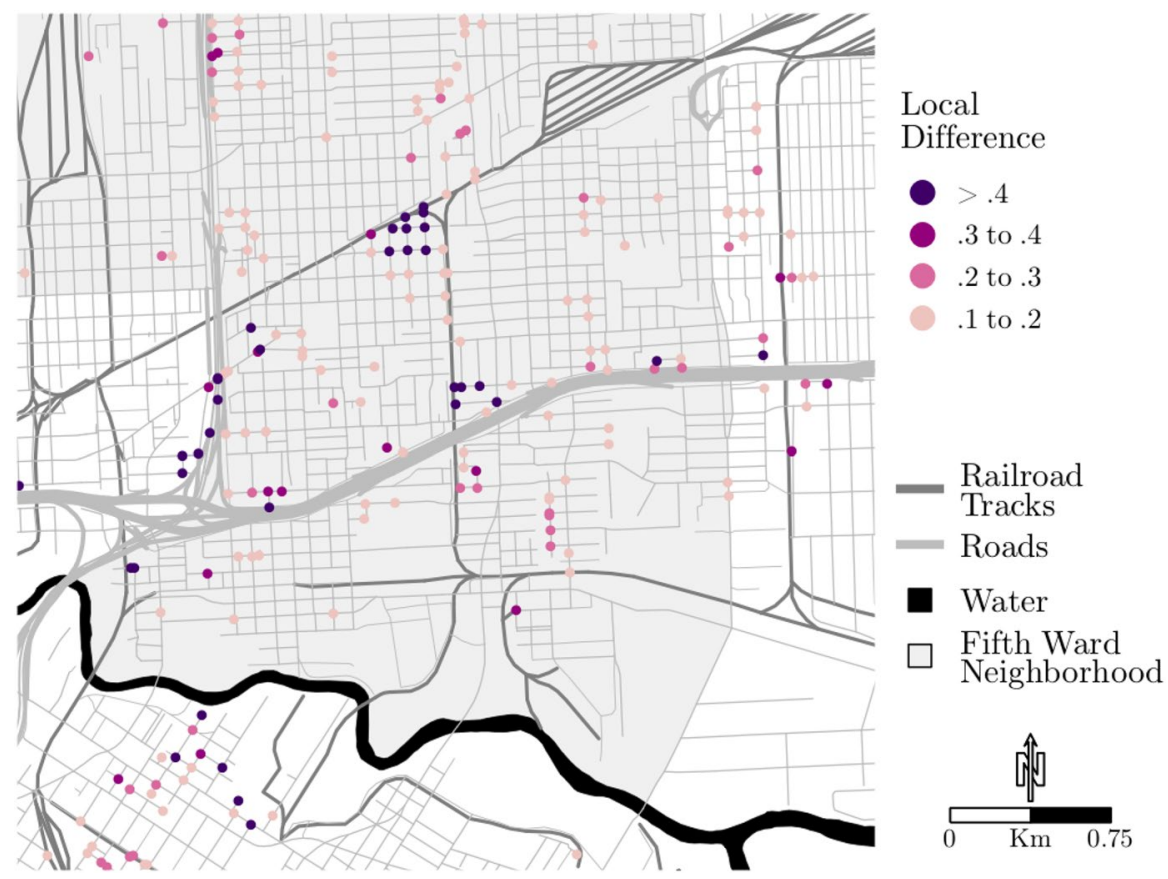

Fig. 3 Difference between road distance and straight line distance segregation measures in the fifth ward neighborhood, reach of local environments $=.25 \mathrm{~km}$

Interstate 45 running between them. Most residents in this area of the Heights are White and most of their neighbors to the east in Northside are Latinx. Figure 4b shows that there are many locations with differences of 0.1 or greater between the road distance and straight line distance segregation measures. Many of the locations with the largest differences are situated along either side of I-45, which suggests that the highway may be a physical barrier that spatially structures the local pattern of segregation.

The limited physical connectivity across I-45 appeared to influence Latinx Northsiders' experiences of stereotyping and discrimination by White Heights stakeholders and White Heights stakeholders' negative racial stereotypes of the Northside. For example, Sadie, a lower middle-class Latina Northside resident, explained the freeway as a physical marker that encouraged White Heights residents to stereotype Latinx Northsiders. She described how a nearby Northside neighbor and business owner dealt with this process when she moved her business from the Heights to Northside:

Well [my neighbor's] business was in the Heights, but the rent was so high, she moved over here. And she's been here six, seven years now. Well even her customers tell her, 'Why did you come over here?' [whispers] You know, she said she got robbed in the Heights two or three times, she's never been robbed here! So it's kind of stereotyped, we're stereotyped, you know. Just- once you 

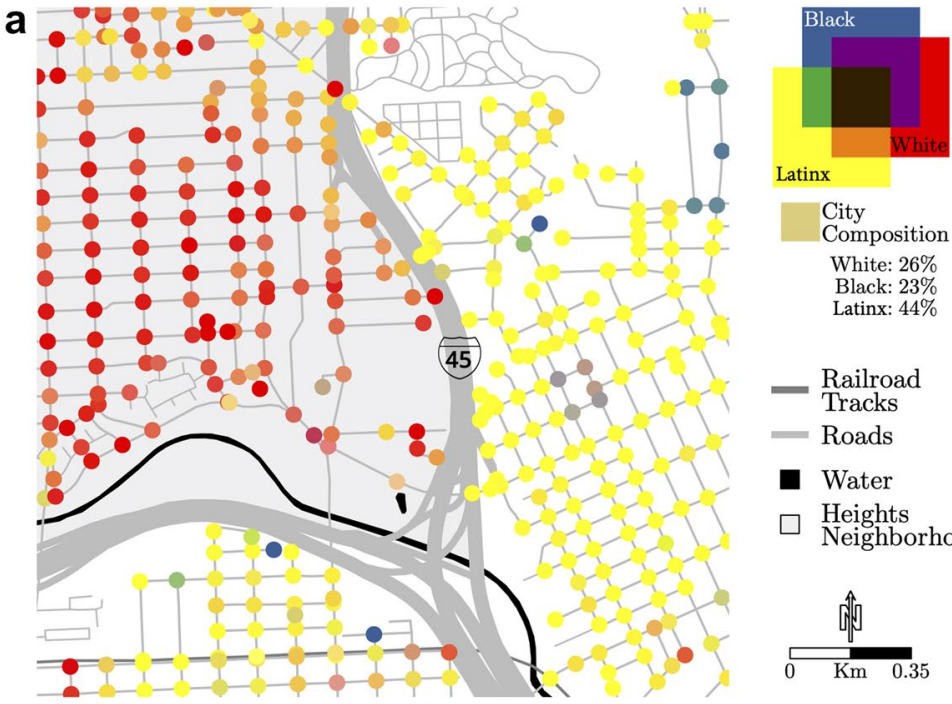

Latinx

City

Composition

White: $26 \%$

Black: $23 \%$

Latinx: $44 \%$

Railroad

Tracks

- Roads

- Water

Heights

Neighborhood

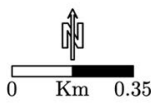

b

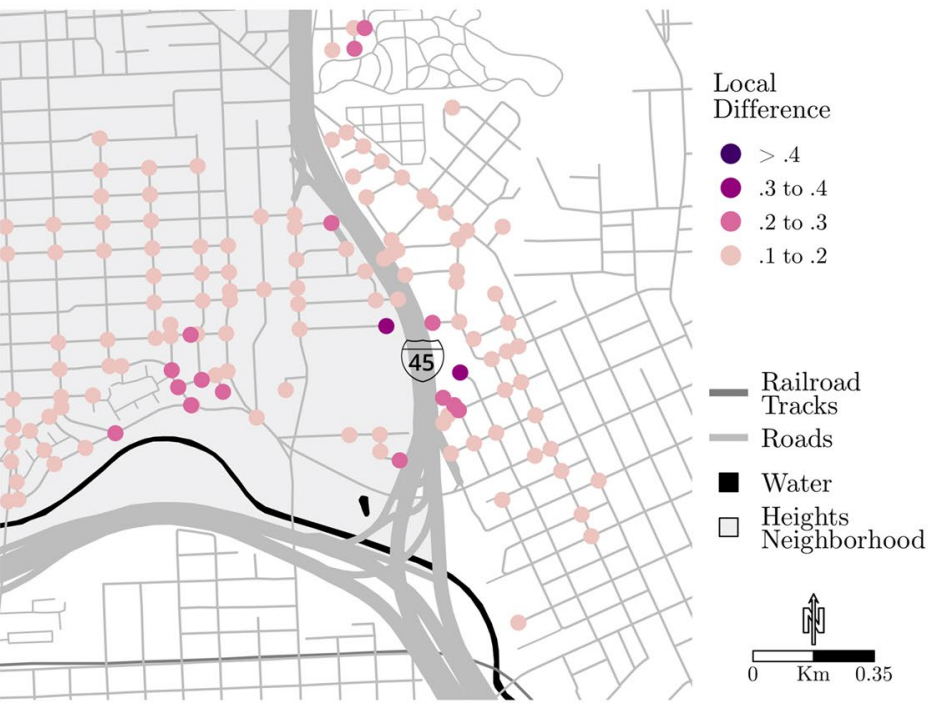

Fig. 4 a Black, Latinx, and White population in the heights neighborhood. b Difference between road distance and straight line distance segregation measures in the heights neighborhood, reach of local environments $=1 \mathrm{~km}$

pass...the freeway, from White Oak [Drive] to here, you know, we're stereotyped. 'Oh, that's Northside, it's bad, it's bad.' It's really not, it's just...I guess we have that title to us.

Mercedes, another middle-aged Latina, was a resident of Fifth Ward at the time of our interview and a former resident of both Northside and the Heights. She believed that Heights residents saw the Northside as "a lower-class neighborhood that's up 
to no good" because "it's on the other side of the- not the tracks, but it's the other side"-clearly referencing Interstate 45. Further, as Sadie's White friend and Northside employee Linda explained, it was the difficulty of "crossing that 45 ...crossing over the interstate" that encouraged the application of such stereotypes.

Similarly, another middle-aged Northside resident, Mateo, described how he believed Interstate 45 was an arbiter of local police officers' negative stereotypes about Northside as well as an obstacle to timely police responses. Specifically comparing the Heights and Northside, Mateo explained,

I mean, police officers, you call the Heights-I was out there at Travis [Elementary in the Heights], something came up, boom! Get on the emergency number, the unit was there like within a minute. Fast. Something happens here on this side [of 45]? You'll be lucky if they come in 15, 20 minutes, or longer. [If] they even show up. ...If it's in the Heights, we'll either- we'll kiss your ass every minute of the day. You're in Northside, oh forget you (emphasis added).

In addition to Mateo's views on policing practices, Alejandro, a Northside resident active in local politics, believed that I-45 affected White Heights residents' racial stereotypes of the Northside neighborhood and their voting behavior. He explained,

I don't think that [White Heights residents] perceive [Northside] in a very good way. I think that they probably have a negative perception about it. ...one of the early voting locations, traditionally, has been in Moody Park [in Northside] and there is always this running discussion many times... amongst [White] people... is it safe to cross 45 ? They see 45 as the dividing line, like is it safe to cross even from one side of the freeway to the other, just to go to Moody Park which isn't very far from the boundary anyway. ... they would rather go to the multiservice center on West Gray than to come to [Moody Park in Northside]...But it's because enough people don't see it as a viable choice and, I have heard, that it's because there is this perception of them not wanting to come. "Them" I say, in general, from the Heights area more affluent, to come to this side of 45.

Despite the voting location at Moody Park (in Northside) being across Interstate 45 from the Heights and thus 'close' in terms of straight-line distance, Alejandro viewed the limited connectivity across I-45 between Heights and Northside as supporting White Heights residents' decisions to vote elsewhere. Further, Houston's political circuit, of which Alejandro was a part, viewed I-45 as a physical barrier that reinforced White voters' desire to distance themselves from a Latinx area they believed to be unsafe.

At the same time Latinx Northside residents described I-45 as a vehicle for the stereotyping and discrimination they experienced, Heights residents and stakeholders, including Trent, a White real estate agent, engaged in such stereotyping, using the I-45 physical barrier in precisely the ways Latinx Northsiders had described. In one interaction with a home-buying client, for example, Trent described the area east of I-45 as "scary" and a "no-man's land." Zach was yet another White Heights stakeholder, a local mortgage banker, who used I-45 as a physical and symbolic barrier between the Heights and Northside. He described Northside as "the next transitional neighborhood," then went on to explain: 
But there's that barrier, the I-45 barrier, the mental barrier on that. But, you know, the reputation that I hear...is it's still kind of like more opportunity up and coming still, but still I mean we're talking about more, say for lack of a better term, a borrower that just can't afford to be here [in the Heights] but still wants to be in town.... But the overall reputation-I mean on a personal level, people kind of look at that as an area that they may not be attracted to, maybe crime may be high (emphasis added).

Zach's explanation illustrates how White Heights stakeholders merged the physical I-45 barrier with a symbolic, or what he calls "mental," barrier to disconnect themselves and the Latinx Northside, which they stereotyped as "scary" and "high crime." In short, Zach, Trent, and other White Heights stakeholders used the Interstate 45 physical barrier-which disconnected them physically from Northside-as a convenient symbolic reference point for disconnecting 'us' (perceived as safe) from Latinx 'them' (perceived as unsafe).

Finally, in Northside, a large tract of undeveloped, former railyard land at the southern tip of the neighborhood limited connectivity to other nearby-and racially distinct-areas (see Fig. 5). The map in Fig. 6a shows the ethnoracial composition of this area of Northside and the area to the south on the opposite side of the undeveloped land. The residents to the north in Northside are predominantly Latinx,

Fig. 5 Undeveloped land that limits connectivity between northside and downtown. Note Photo taken in January 2014 by Elizabeth Korver-Glenn

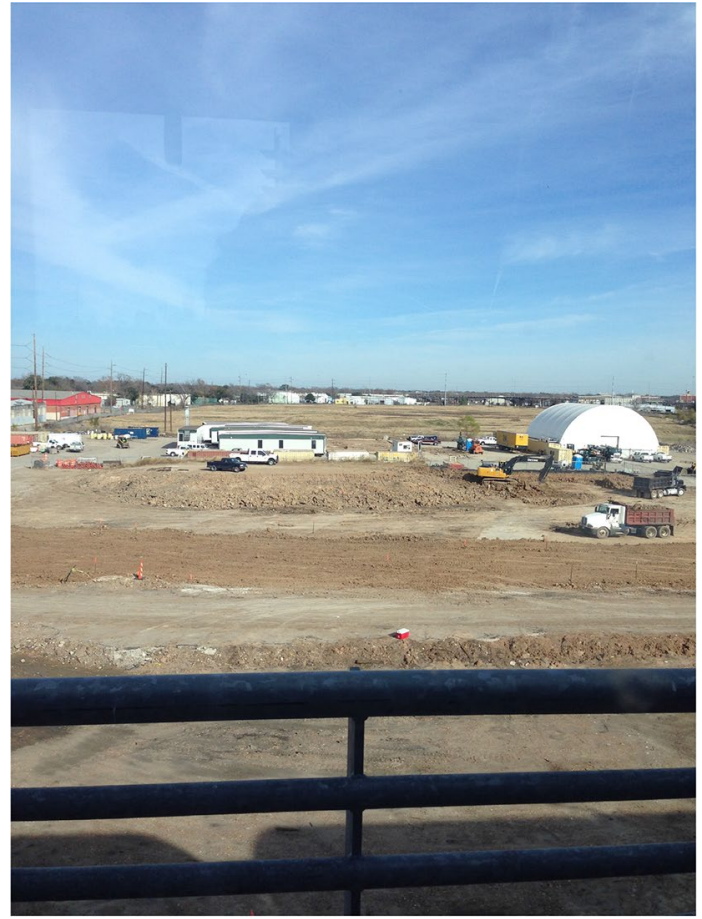

Note: Photo taken in January 2014 by

Elizabeth Korver-Glenn 
a

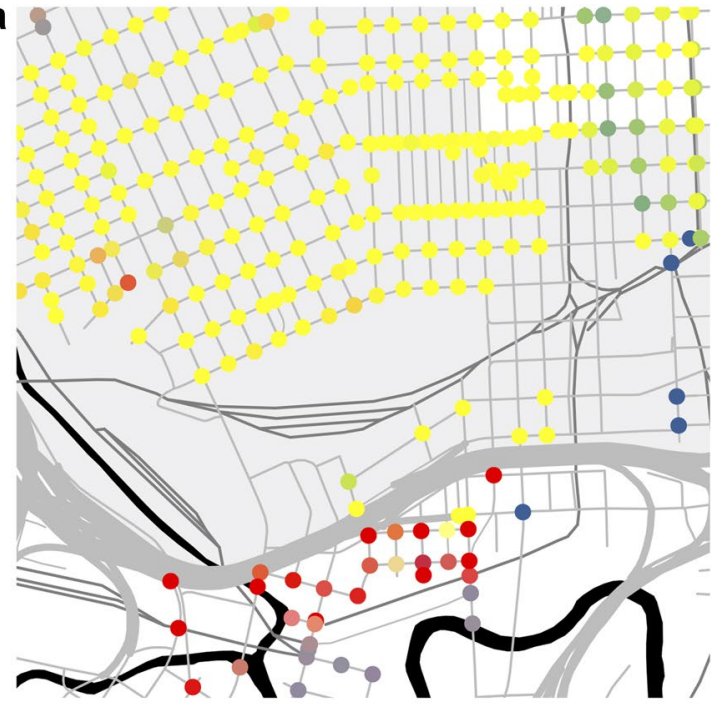

b

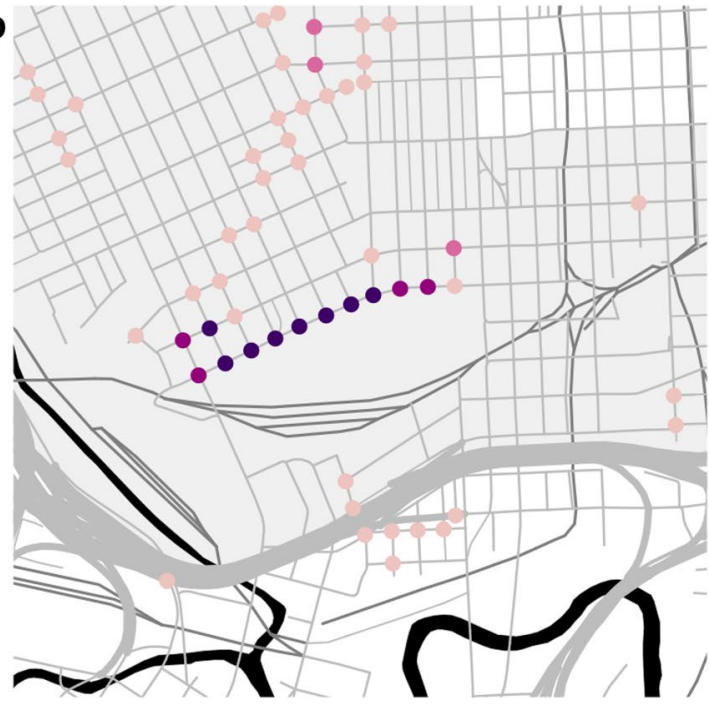

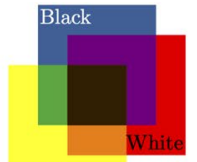

Latinx

City

Composition

White: $26 \%$

Black: $23 \%$

Latinx: $44 \%$

Railroad

Tracks

Roads

- Water

Northside

Neighborhood

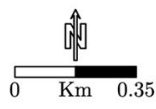

Local

Difference

$>.4$

. 3 to .4

- 2 to .3

(1) 1 to .2

Railroad Tracks

- Roads

- Water

Northside

Neighborhood

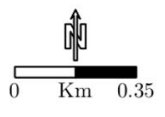

Fig. 6 a Black, Latinx, and White population in the northside neighborhood. b Difference between road distance and straight line distance segregation measures in the northside neighborhood, reach of local environments $=1 \mathrm{~km}$

while the population to the south are largely White. Figure 6b shows that there are locations with large differences between the road distance and straight line distance segregation measures on both sides of the undeveloped land, but the differences are particularly large for the locations on Burnett Street in Northside where most of the differences are greater than 0.4. These differences suggests that this undeveloped land poses a physical barrier between nearby areas and spatially structures a local pattern of segregation. 
During fieldwork, it was clear that this physical barrier was a matter of great concern to Northside residents. There were only two main paths to connect the Latinx residents in Northside to the predominantly White area just south of the barrier in downtown: Main Street (western side of the neighborhood) and Hardy Street (eastern side of the neighborhood). However, during fieldwork, ongoing construction on Main Street near downtown completely closed off this particular route to residents, bringing the barrier this undeveloped land posed into sharp relief. Together with the physical barrier of undeveloped land south of Burnett Street, the construction was the subject of many neighborhood association meetings, in which residents regularly brought their about being cut off from other areas to the attention of local political and development representatives.

At one such meeting held in March 2015, local residents waited to hear about an update on this particular construction project. A representative from Northside's city council member's office, Juanita, explained to those in attendance that the construction project was about $65 \%$ complete, adding that there would be an "art component" to the newly constructed Main Street tunnel, about which the councilman wanted residents' input. But residents were more concerned about their inability to get around the barrier the undeveloped land imposed and access downtown. One resident asked, "Is there going to be a path under there still?" "Yes," replied Juanita, there will still be a path." Another resident jumped in, expressing concern about the expected completion date for the construction project: "Is it really going to be finished in June? There's no concrete." "It's on schedule," said Juanita, "I'll have more detailed information on the pathways and what you can expect once it's complete at the next meeting."

Local speculation on impending construction on Hardy Street-the other main artery allowing residents to get around the large tract of undeveloped landprompted similar concerns. One local real estate agent, Craig, believed that if the Hardy Street bridge to downtown was removed or closed, the entire neighborhood would suffer:

So just that road [Hardy Street] - if that road wasn't there, this area-you could probably scratch off the list of being a great place. But because that road is there, and it connects, that right there is the lifeline. If they ever tore out that bridge over the railroad tracks there-if that was gone, you'd see this area shrivel up and die...

The abandoned railyard limits connectivity between Northside and nearby areas, particularly Houston's predominantly White downtown to the south, and spatially structures the local pattern of segregation.

\section{Discussion and Conclusion}

By homing in on physical barriers and how such barriers are experienced socially, our study contributes to a deeper understanding of segregation by examining the role of the built environment in creating separate residential spaces and facilitating ethnoracial segregation. The results also enable a deeper understanding of how the built environment 
shapes individuals' perceptions of their own and others' residential contexts and inform future research on the relationship between segregation and other sources of urban inequality, such as residents' access to economic resources or exposure to violent crime.

We first examined the broader context of spatial segregation in the city of Houston. We found that Houston has a pattern of both macro-scale and micro-scale spatial segregation, meaning that it contains both large, racially homogenous areas and smaller racial enclaves. We used the Spatial Proximity and Connectivity method to examine the extent to which physical barriers structure these patterns of segregation. We found differences between road distance and straight line distance segregation measures at the city- and neighborhood-level. The positive differences between the two measures suggest that physical barriers contribute to higher levels of racial segregation within the city. Then, we described how physical barriers emerged as salient aspects of lived experience in qualitative interviews and ethnographic fieldwork. We found that multiple physical barriers such as highways and railroad tracks appeared to buttress Houstonians' perceptions of social (i.e. ethnoracial) difference and limit social and physical connectivity across areas separated by these barriers.

Then, to examine how physical barriers may shape local residents' experiences of segregation, we chose three racially distinct urban Houston neighborhoods as microlevel case studies. Pairing quantitative analyses of physical barriers in the three areas with in-depth interviews and ethnographic observations, we highlighted how physical barriers such as train tracks, freeways, and undeveloped land affected residents' perceptions and experiences of racial segregation at the local level. These physical barriers, as visible, durable features of the built environment, appeared to inhibit physical connectivity between neighborhoods and facilitated stereotyping and other forms of symbolic division between residents and other stakeholders active in each neighborhood.

The present study provides an in-depth descriptive analysis of a single city, but it does not establish a causal relationship between physical barriers and segregation levels. Our qualitative data are also limited in that they do not allow us to examine in-depth how physical barriers affect everyday social interactions across these barriers, or lack thereof. Additionally, our quantitative analysis in particular focuses only on race and not class distinctions between areas. Yet these limitations suggest fruitful possibilities for future research. Future work should examine change in urban built environments and segregation patterns over time to go beyond a descriptive analysis of association. Moreover, future research should also examine class distinctions in addition to racial division across areas, and should apply a mixed-methods approach to other cities with different race-and-class dynamics. Future research should also home in on whether and how physical barriers are associated with (a lack of) social interactions between ethnoracially distinct areas.

Broadly, this study enriches our understanding of the patterns and meanings of racial segregation as well as the processes that contribute to racial segregation. For instance, the social structural sorting perspective posits that individuals accumulate community knowledge through their racialized lived experiences (Krysan \& Crowder, 2017; Lee, 2019); this racialized community knowledge affects their residential choices, contributing to racial segregation. Our findings suggest that physical barriers are an important aspect of community knowledge formation: they make cities 
"legible" (Lynch, 1960) when infused with collective symbolic meaning and seem to be associated with both physical and social disconnection.

Our study also has implications for research on race, space, and placemaking. Specifically, local actors often interpret and experience physical barriers-similar to architecture and architectural regulations (Lung-Amam, 2013), housing stock (Lipsitz, 2011), and located institutions such as schools (Bell, 2020)_in heterogeneous ways. Put another way, physical barriers can be contested symbols that are associated with diverging views of and actions toward space. For example, White Heights stakeholders routinely interpreted the Interstate 45 barrier between Northside and the Heights as a symbol of Northside's perceived criminality and lack of safety; their constructions of symbolic difference vis-à-vis I-45 undergirded the physical and social disconnectivity associated with I-45. By contrast, although Latinx Northside stakeholders knew that White Heights actors viewed and treated I-45 in this way, they often contested this meaning. Such contestation is illustrated, for example, by Sadie's comment (above), "[Northside]'s really not [bad], it's just...I guess we have that title to us" (see also Korver-Glenn, 2014, 2015). Latinx Northsiders experienced I-45 as a mechanism of physical and social disconnection. But they did not infuse it with the same symbolic meaning as White Heights actors. They also did not mirror White Heights actors' meaning-making: that is, they did not use Interstate 45 to associate the Heights with criminality or danger. In short, while physical barriers may disconnect people on each side of the barrier in the same ways, the meaning actors ascribe to these barriers may vary. Whether and how this variation unfolds along race, class, gender, household status, or other socially salient lines has important implications for how physical barriers matter for multiple forms of urban inequality and resistance to such inequality.

In sum, combining the complementary strengths of quantitative spatial analyses with analyses of in-depth interview and ethnographic methods (see Small, 2011) allows us to pinpoint with geographic specificity where and to what extent spatial segregation is occurring and how such segregation matters for residents. Our study indicates that physical barriers are easy-to-read signals of social distinction. As durable features of the urban built environment, these signals shape whether and how residents of different areas perceive and act in ways that reinforce existing patterns of ethnoracial segregation.

\section{Appendix}

The Divergence Index is based on relative entropy-an information theoretic measure also known as Kullback-Leibler (KL) divergence (Cover \& Thomas, 2006; Kullback, 1987). The Divergence Index measures the same concept of segregation as the Dissimilarity Index. Both indexes measures the evenness dimension of segregation (Massey \& Denton, 1988) by comparing the residential distribution of groups to an even distribution in which groups are distributed proportionally across residential environments. However, the Dissimilarity Index uses a linear function to evaluate segregation and the Divergence Index uses a likelihood function. This means that with the Dissimilarity Index, any departure from evenness is treated equally, 
whereas the Divergence Index evaluates small departures from evenness as contributing proportionally less to segregation than larger departures from evenness. ${ }^{10}$ One advantage of using a likelihood function is that the Divergence Index can easily be decomposed to analyze how much of the overall segregation in a city occurs within vs. between population groups or spatial areas (Roberto, 2016).

In this study, we focus on the segregation of Black, Latinx, and White residents in the city of Houston, the city's three largest racial and ethnic groups. ${ }^{11}$ The population of Houston is 23 percent Black, 44 percent Latinx, and 26 percent White. Despite the city's diversity, residential environments in Houston tend to be segregated. Table 3 provides an overview of city segregation using three indexes: the Index of Dissimilarity (Reardon and O'Sullivan 2004) and the aspatial and spatial versions of the Divergence Index (Roberto, 2016, 2018). The two-group Dissimilarity Index is the most commonly used measure of segregation. The Dissimilarity Index and the aspatial version of the Divergence Index both measure segregation for census tracts, the mostly commonly used geographic unit for measuring segregation. ${ }^{12}$ The spatial Divergence Index is the population-weighted average of the road network distance segregation measure for all nodes in the city using local environments with a reach of $.5 \mathrm{~km} .{ }^{13}$

Table 3 reports two- and three-group indexes of segregation for Houston. The three indexes reveal moderate to high levels of segregation in Houston. ${ }^{14}$ The Dissimilarity Index tends to show higher levels of segregation than the aspatial and spatial versions of the Divergence Index, which may be due to differences in their mathematical bases: the Dissimilarity Index uses a linear function to evaluate segregation and the Divergence Index uses a likelihood function. ${ }^{15}$ Despite the apparent differences, the tract level segregation scores for the indexes have a strong correlation $(r \geq .94)$.

\footnotetext{
${ }^{10}$ For example, when measuring segregation with the Divergence Index, in a city with two groups that are each $50 \%$ of the population, the difference between the segregation score for an area with 45-55 proportions and an area with 40-60 proportions is smaller than the difference between the segregation score for an area with 5-95 proportions and an area with 0-100 proportions. In other words, the further from evenness the local composition is, the more surprising each unit of departure from the city's composition becomes, and the higher the segregation score will be. However, with the Dissimilarity Index, any departure from evenness contributes equally to segregation.

${ }^{11}$ Using U.S. Census Bureau's categories of race and ethnicity, we define three ethnoracial groups: Hispanic/Latino of any race ("Latinx"), non-Hispanic Black ("Black"), and non-Hispanic White ("White").

${ }_{12}$ The boundaries of census tracts do not conform to city boundaries (i.e., tracts are not geographically nested within places). For tracts that straddle the city boundary, we aggregate the population of the tracts' blocks that are within the city and exclude population outside the city.

${ }^{13}$ Although census tracts vary in geographic size, a local environment with a reach of $.5 \mathrm{~km}$ approximates the size of a typical tract in Houston.

${ }^{14}$ Values of the Dissimilarity Index between .3 and .6 are conventionally considered to indicate "moderate" segregation and values above .6 are considered to be "high" (Kantrowitz 1979; Massey and Denton 1988).

15 The Divergence Index is conceptually similar to the Dissimilarity Index, but it uses a likelihood function to evaluate segregation rather than a linear function. With the Dissimilarity Index, any departure from evenness is treated equally. The Divergence Index evaluates small departures from evenness as contributing proportionally less to segregation than larger departures from evenness. For example, in a city with two groups that are each $50 \%$ of the population, the difference between the segregation score for a 45-55 tract and a 40-60 tract is smaller than the difference between the segregation score for a 5-95 tract and a 0-100 tract. The further from evenness the composition is, the more each unit of difference contributes to segregation.
} 
Table 3 Racial and ethnic segregation in Houston

Dissimilarity index (census tracts)
Divergence index (census tracts)
Road distance divergence index $(.5 \mathrm{~km}$ reach)

\begin{tabular}{llll}
\hline Black-White & .70 & .50 & .54 \\
Latinx-White & .60 & .33 & .36 \\
Black-Latinx & .53 & .28 & .31 \\
Black-Latinx-White & .55 & .51 & .56 \\
\hline
\end{tabular}

Source: Authors' calculations using the 2010 decennial census

Results for the two-group indexes show that segregation is moderately high in Houston. Segregation is higher for Black and White residents than for Latinx and White or Black and Latinx residents. The level of Black-White segregation in Houston's in census tracts is similar to Baltimore (dissimilarity index: .69, divergence index: .43) and Philadelphia (dissimilarity index: .74, divergence index: .54), and the level of Latinx-White segregation is similar to Chicago (dissimilarity index: .61, divergence index: .37) and somewhat higher than Miami (dissimilarity index: .50, divergence index: .13).

Black-Latinx-White segregation in Houston is also moderately high, with levels above .5 across the three indexes. Black-Latinx-White segregation in Houston's in census tracts is similar to Los Angeles (dissimilarity index: .58, divergence index: .49) and somewhat lower than New York (dissimilarity index: .62, divergence index: .66).

The spatial segregation of Black, Latinx, and White residents in Houston varies across geographic scales - we use local environments with a reach of $.25 \mathrm{~km}, .5 \mathrm{~km}$, $1 \mathrm{~km}, 2 \mathrm{~km}, 3 \mathrm{~km}, 4 \mathrm{~km}$, and $6 \mathrm{~km}$. Figure 7 presents the results for the road distance and straight line distance segregation measures. The level of segregation for both measures steadily decreases as the reach of local environments increases. The road distance segregation measure decreases from .59 when the reach is $.25 \mathrm{~km}$ to .26 when the reach is $6 \mathrm{~km}$, and the straight line distance segregation measure decreases from .58 when the reach is $.25 \mathrm{~km}$ to .21 when the reach is $6 \mathrm{~km}$.

Although the segregation measures both steadily decrease as the reach of local environments increases, as seen in Fig. 7, the level of segregation is consistently higher for the road distance segregation measure. By comparing the levels of segregation revealed by the road distance and straight line distance segregation measures, we can analyze how road (dis)connectivity and the presence of physical barriers are associated with segregation. Positive differences indicate that taking into account the connectivity and barriers between locations reveals that there is greater separation between ethnoracial groups, compared to assuming that there is unimpeded connectivity between residential locations (as implied by the straight line distance segregation measure).

Figure $7 \mathrm{~b}$ presents the average difference between the road distance and straight line distance segregation measures in Houston, which ranges from .02 to .05 for local environments with reaches of $.25 \mathrm{~km}$ to $6 \mathrm{~km}$. Although the city-level 
a

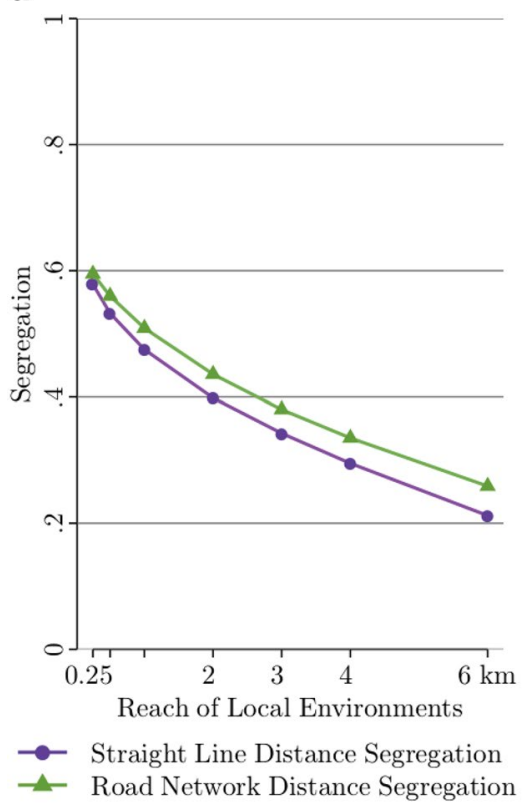

b

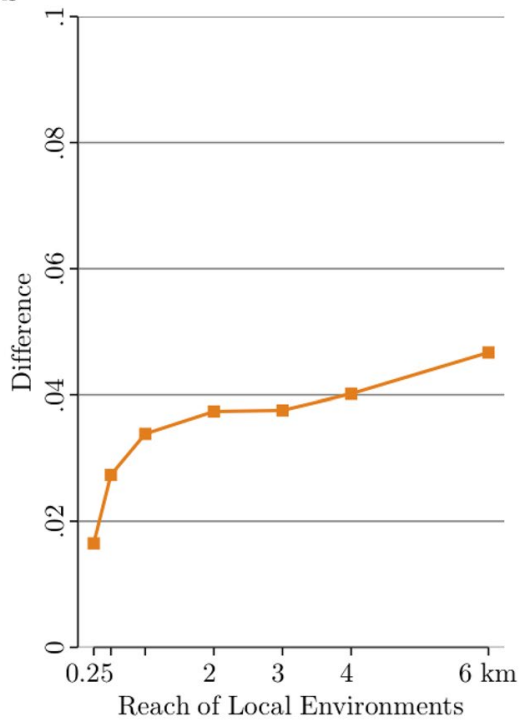

Fig. 7 a Road distance and straight line distance segregation measures (Black-Latinx-White segregation). b Difference between road distance and straight line distance segregation measures (Black-LatinxWhite segregation)

difference between the segregation measures is relatively small, this difference represents the population-weighted average difference between the segregation measures for all nodes in the city, including areas where the roads are well-connected and where there are no physical barriers. In such areas, the local environments constructed with road distance and straight line distance will have a similar composition and we would not expect there to be a difference between the two segregation measures. Therefore, even small positive differences in the city-level results are noteworthy and suggest that road disconnectivity and physical barriers facilitate greater separation between ethnoracial groups and higher levels of segregation in local areas within the city

Acknowledgments The authors wish to thank Jacob Faber and Jackelyn Hwang for helpful comments on earlier drafts of this paper. This research was supported in part by the James S. McDonnell Foundation Postdoctoral Fellowship Award in Studying Complex Systems, the Princeton Institute for Computational Science and Engineering (PICSciE) and the Office of Information Technology's High Performance Computing Center at Princeton University, and the Rice University Social Sciences Research Institute.

\section{Declarations}

Conflict of interest On behalf of all authors, the corresponding author states that there is no conflict of interest. 
Open Access This article is licensed under a Creative Commons Attribution 4.0 International License, which permits use, sharing, adaptation, distribution and reproduction in any medium or format, as long as you give appropriate credit to the original author(s) and the source, provide a link to the Creative Commons licence, and indicate if changes were made. The images or other third party material in this article are included in the article's Creative Commons licence, unless indicated otherwise in a credit line to the material. If material is not included in the article's Creative Commons licence and your intended use is not permitted by statutory regulation or exceeds the permitted use, you will need to obtain permission directly from the copyright holder. To view a copy of this licence, visit http://creativecommons.org/licen ses/by/4.0/.

\section{References}

Ananat, E. O. (2011). The wrong side(s) of the tracks: The causal effects of racial segregation on urban poverty and inequality. American Economic Journal: Applied Economics, 3(2), 34-66

Anderson, E. (1990). Streetwise: Race, class, and change in an urban community. University of Chicago Press.

Appel, A. (2012). Tear down fence? Idea shelved. New Haven Independent, Aug 30. https://www.newha venindependent.org/index.php/archives/entry/tear_down_fence_never_mind/.

Armborst, T., D’Oca, D., \& Theodore, G. (Eds). (2017). The arsenal of exclusion/Inclusion. Actar.

Atkinson, R., \& Flint, J. (2004). Fortress UK? Gated communities, the spatial revolt of elites and timespace trajectories of segregation. Housing Studies, 19(6), 875-892

Bader, M. D. M., \& Krysan, M. (2015). Community attraction and avoidance in Chicago what's race got to do with it? The ANNALS of the American Academy of Political and Social Science, 660(1), 261-281

Bass, P. (2014). New Haven-Hamden "Berlin Wall” coming down. New Haven Independent, May 4, 2014. Retrieved http://www.newhavenindependent.org/index.php/archives/entry/new_haven-hamden_berlin_wall_coming_down.

Bell, M. C. (2020). Located institutions: Neighborhood frames, residential preferences, and the case of policing. American Journal of Sociology, 125(4), 917-973

Besbris, M. (2016). Romancing the home: Emotions and the interactional creation of demand in the housing market. Socio-Economic Review, 14(3), 461-482

Besbris, M. (2020). Upsold: Real estate agents, prices, and neighborhood inequality. University of Chicago Press.

Besbris, M., \& Faber, J. W. (2017). Investigating the relationship between real estate agents, segregation, and house prices: steering and upselling in New York State. Sociological Forum, 32(4), 850-873

Besbris, M., Faber, J. W., Rich, P., \& Sharkey, P. (2015). Effect of neighborhood stigma on economic transactions. Proceedings of the National Academy of Sciences, 112, 4994-4998

Blakely, E. J., \& Snyder, M. G. (1997). Fortress America: Gated communities in the United States. Brookings Institution Press.

Brown, L. A., \& Chung, S.-Y. (2006). Spatial segregation, segregation indices and the geographical perspective. Population, Space and Place, 12(2), 125-143

Charles, C. Z. (2006). Won't you be my neighbor: Race, class, and residence in Los Angeles. Russell Sage Foundation.

Connolly, N. D. B. (2014). A world more concrete: Real estate and the remaking of Jim Crow South Florida. University of Chicago Press.

Cover, T. M., \& Thomas, J. A. (2006). Elements of information theory. Wiley-Interscience.

Dimento, J. F. C., \& Ellis, C. (2012). Changing lanes: Visions and histories of urban freeways. MIT Press.

Doherty, C. (2016). 5 Facts about Trump supporters' views of immigration. Pew Research Center. Retrieved February 16, 2017. http://www.pewresearch.org/fact-tank/2016/08/25/5-facts-abouttrump-supporters-views-of-immigration/.

Emerson, M. O., \& Smiley, K. T. (2018). Market cities and people cities: The shape of our urban future. New York: NYU Press. 
Feagin, J. R. (1988). Free enterprise city: Houston in political and economic perspective. Rutgers University Press.

Fifth Ward CRC. (2011). The fifth ward housing study: Our space is a great place. Report on Harris County Tax Incremental Reinvestment Zone \#18 obtained during fieldwork.

Flippen, C. (2004). Unequal returns to housing investments? A study of real housing appreciation among Black, White, and Hispanic Households. Social Forces, 82(4), 1523-1551

Folch, D. C., \& Rey, S. J. (2016). The centralization index: A measure of local spatial segregation. Papers in Regional Science, 95(3), 555

Fowler, C. S. (2015). Segregation as a multiscalar phenomenon and its implications for neighborhoodscale research: The case of South Seattle 1990-2010. Urban Geography, 37(1), 1-25

Friese, S. (2012). Qualitative data analysis with ATLAS.ti. London: Sage.

Grannis, R. (1998). The importance of trivial streets: Residential streets and residential segregation. American Journal of Sociology, 103(6), 1530-1564

Grannis, R. (2005). T-communities: Pedestrian street networks and residential segregation in Chicago, Los Angeles, and New York. City and Community, 4(3), 295-321

Howell, J., \& Emerson, M. O. (2018). Preserving racial hierarchy amidst changing racial demographics: How neighbourhood racial preferences are changing while maintaining segregation. Ethnic and Racial Studies, 41(15), 2770-2789

Howell, J., \& Korver-Glenn, E. (2018). Neighborhoods, race, and the twenty-first-century housing appraisal industry. Sociology of Race and Ethnicity, 4(4), 473-490

Hunter, A. (1974). Symbolic communities: The persistence and change of Chicago's local communities. University of Chicago Press.

Hwang, J. (2016). The social construction of a gentrifying neighborhood: Reifying and redefining identity and boundaries in inequality. Urban Affairs Review, 52(1), 98-128

Jackson, K. (1985). Crabgrass frontier: The suburbanization of the United States. Oxford University Press.

Jargowsky, P. (2015). Architecture of segregation: Civil unrest, the concentration of poverty, and public policy. The Century Foundation.

Kantrowitz, N. (1979). Racial and ethnic segregation in Boston: 1830-1970. The Annals of the American Academy of Political and Social Science, 441, 41-54

Korver-Glenn, E. (2014). Middle-class Mexican Americans, neighborhood affect, and redevelopment in Houston's northside barrio. City \& Community, 13(4), 381-402

Korver-Glenn, E. (2015). (Collective) memory of racial violence and the social construction of the hispanic category among Houston hispanics. Sociology of Race and Ethnicity, 1(3), 424-438

Korver-Glenn, E. (2018a). Compounding inequalities: How racial stereotypes accumulate across the stages of housing exchange. American Sociological Review, 83(4), 627-656

Korver-Glenn, E. (2018b). Brokering ties and inequality: How white real estate agents recreate advantage and exclusion in urban housing markets. Social Currents, 5(4), 350-368

Korver-Glenn, E. (2021). Race brokers: Housing markets and durable segregation in 21 st century urban America. Oxford University Press.

Kramer, R. (2017). Defensible spaces in Philadelphia: Exploring neighborhood boundaries through spatial analysis. RSF: The Russell Sage Foundation Journal of the Social Sciences, 3(2), 81

Krysan, M., \& Crowder, K. (2017). Cycle of segregation: Social processes and residential stratification. Russell Sage Foundation.

Krysan, M., \& Bader, M. D. M. (2009). Racial blind spots: Black-White-Latino differences in community knowledge. Social Problems, 56(4), 677-701

Krysan, Maria, Kyle Crowder, and Michael DM Bader. 2014. Pathways to residential segregation. Choosing Homes, Choosing Schools 27-63.

Kullback, S. (1987). Letters to the editor. The American Statistician, 41, 338-341

Lamont, M., \& Molnár, V. (2002). The study of boundaries in the social sciences. Annual Review of Sociology, 28, 167-195

Lara-Millán, A., \& Cleve, N. G. V. (2017). Interorganizaitonal utility of welfare stigma in the criminal justice system. Criminology, 55(1), 59-84

Lareau, A. (2012). Using the terms hypothesis and variable for qualitative work: A critical reflection. Journal of Marriage and Family, 74, 671-677

Lee, B. A., Reardon, S. F., Firebaugh, G., Farrell, C. R., Matthews, S. A., \& O'Sullivan, D. (2008). Beyond the census tract: Patterns and determinants of racial segregation at multiple geographic scales. American Sociological Review, 73(5), 766-791 
Lee, C. A. (2019). 'Working towards a better future for ourselves': Neighborhood choice of Middle-Class Latino and Asian homeowners in Los Angeles. Journal of Urban Affairs. https://doi.org/10.1080/ 07352166.2019 .1657022

Legewie, J. (2018). Living on the edge: Neighborhood boundaries and the spatial dynamics of violent crime. Demography, 55(5), 1957-1977

Legewie, J., \& Schaeffer, M. (2016). Contested boundaries: Explaining where ethnoracial diversity provokes neighborhood conflict. American Journal of Sociology, 122(1), 125-161

Lewis, V., Emerson, M. O., \& Klineberg, S. L. (2011). Who we'll live with: Neighborhood racial composition preferences of Whites, Blacks and Latinos. Social Forces, 89(4), 1385-1408

Lipsitz, G. (2011). How racism takes place. Temple University Press.

Logan, J. R. (2017). Racial segregation in postbellum southern cities: The case of Washington, D.C. Demographic Research, 36, 1759-1784

Low, S. (2001). The edge and the center: Gated communities and the discourse of urban fear. American Anthropologist, 103(1), 45-58

Lung-Amam, W. (2013). That 'Monster House' is my home: The social and cultural politics of design reviews and regulations. Journal of Urban Design, 18(2), 220-241

Lynch, K. (1960). The image of the city. MIT Press.

Massey, D. S., \& Denton, N. A. (1988). The dimensions of residential segregation. Social Forces, 67(2), 281-315

Mohl, R. A. (2002). The interstates and the cities: Highways, housing, and the freeway revolt. Poverty and Race Research Action Council 1-109.

Morrill, R. L. (1991). On the measure of geographic segregation. Geography Research Forum, 11(1), $25-36$

Mueller, B. (2014). In Connecticut, breaking a barrier between a suburb and public housing. New York Times, July 11. Retrieved https://www.nytimes.com/2014/07/12/nyregion/in-connecticut-breakingbarrier-between-a-suburb-and-public-housing.html.

O'Sullivan, D., \& Wong, D. W. S. (2007). A surface-based approach to measuring spatial segregation. Geographical Analysis, 39(2), 147-168

Owens, A., Reardon, S. F., \& Jencks, C. (2016). Income segregation between schools and school districts. American Educational Research Journal, 53(4), 1159-1197

Pearce, L. D. (2012). Mixed methods inquiry in sociology. American Behavioral Scientist, 56(6), 829-848

Reardon, S. F., \& O'Sullivan, D. (2004). Measures of spatial segregation. Sociological Methodology, $34(1), 121-162$

Roberto, E. (2016). The divergence index: A decomposable measure of segregation and inequality. arXiv. org. Retrieved December 5, 2016. http://arxiv.org/abs/1508.01167v2.

Roberto, E. (2018). The spatial proximity and connectivity (SPC) method for measuring and analyzing residential segregation. Sociological Methodology, 48(1), 182-224

Ross, S. L., \& Turner, M. A. (2005). Housing discrimination in metropolitan America: Explaining changes between 1989 and 2000. Social Problems, 52(2), 152-180

Schindler, S. (2015). Architectural exclusion: Discrimination and segregation through physical design of the built environment. The Yale Law Journal, 124(6), 1934-2024

Semuels, A. (2015). How to decimate a city. The Atlantic.

Shelton, K. (2017). Building a better Houston: Highways, neighborhoods, and infrastructural citizenship in the 1970s. Journal of Urban History, 43(3), 421-444

Small, M. L. (2009). How many cases do I need?' On science and the logic of case selection in fieldbased research. Ethnography, 10(1), 5-38

Small, M. L. (2011). How to conduct a mixed methods study: Recent trends in a rapidly growing literature. Annual Review of Sociology, 37, 57-86

Sugrue, T. J. (2005). The origins of the urban crisis: Race and inequality in Postwar Detroit. Princeton University Press.

Suttles, G. D. (1972). The social construction of communities. University of Chicago Press.

Thomas, M. E., Moye, R., Henderson, L., \& Horton, H. D. (2018). Separate and unequal: The impact of socioeconomic status, segregation, and the great recession on racial disparities in housing values. Sociology of Race and Ethnicity, 4(2), 229-244

Timmermans, S., \& Tavory, I. (2012). Theory construction in qualitative research: From grounded theory to abductive analysis. Sociological Theory, 30(3), 167-186 
Turner, M. A., Santos, R., Levy, D. K., Wissocker, D., Aranda, C., Pitingolo, R., \& Institute, T. U. (2013). Housing discrimination against racial and ethnic minorities 2012. U.S. Department of Housing and Urban Development.

U.S. Census Bureau. (2011) 2010 Census Summary File 1-United States.

U.S. Census Bureau. (2012). 2010 TIGER/Line Shapefiles.

U.S. Census Bureau. (2015). QuickFacts: Houston city, Texas. Retrieved February 16, 2017. https://www. census.gov/quickfacts/table/PST045215/4835000,00.

Wang, Qi., Phillips, N. E., Small, M. L., \& Sampson, R. J. (2018). Urban mobility and neighborhood isolation in America's 50 largest cities. Proceedings of the National Academy of Sciences, 115(30), 7735-7740

White, M. J. (1983). The measurement of spatial segregation. American Journal of Sociology, 88(5), 1008-1018

Xu, H., Logan, J. R., \& Short, S. E. (2014). Integrating space with place in health research: a multilevel spatial investigation using child Mortality in 1880 Newark, New Jersey. Demography, 51(3), $811-834$

Publisher's Note Springer Nature remains neutral with regard to jurisdictional claims in published maps and institutional affiliations. 